\title{
An integrated system for ultra precision machine tool design in conceptual and fundamental design stage
}

\author{
Wanqun Chen ${ }^{1 *}$, Xichun $\mathrm{Luo}^{2}$, Hao Su${ }^{1}$, Frank Wardle ${ }^{3}$
}

1. Center for Precision Engineering, Harbin Institute of Technology, Harbin 150001, P. R. China

2. Department of Design, Manufacture \& Engineering Management, University of Strathclyde, Glasgow, G1 1XQ, UK

3. UPM Ltd., Mill Lane, Stanton Fitzwarren, Swindon, SN6 7SA, UK

W. Q. Chen, Tel: 86-0451-86413840, Fax: 86-0451-86415244, E-mail: chwq@hit.edu.cn

Abstract: This paper presents an integrated system used for ultra precision machine tool (UPMT) design in conceptual and fundamental design stage. This system is based on the dynamics, thermodynamics and error budget theory. The candidate configurations of the machine tool are first selected from the configuration library or a novel configuration designed by the user, according to the functions of the machine tool expected to realize. Then the appropriate configuration is given by comparing the stiffness chain, dynamic performance, thermal performance and the error budget of each candidate configuration. Consequently, the integrated design system enables the conceptual and fundamental of the UPMT to be designed efficiently with theoretical foundation. The proposed system was used for several UPMTs design, which demonstrate the effectiveness of the integrated design system.

Keywords: Integrated system; ultra precision machine tool; machine design; dynamic analysis; thermal analysis; error budget 


\section{Introduction:}

During the last few decades, the demand for high-precision parts has greatly increased not only for changing our lives in terms of increased living standards, but also for the national defense, energy, space exploration, and so on [1-3]. Precision machines are becoming even more essential in modern industry which directly affect machining accuracy, repeatability, productivity and efficiency. Therefore, design for higher precision is becoming much more important due to the rapidly increasing need for high accuracy machines, instruments and consumer products $[4,5]$.

Regarding machine tools, the structural design is critical since the mechanical structure not only provides the support and accommodation for all the machine's components but also contributes to dynamics performance possessed of the machine tool [6-10]. Moreover, the structure is one of the critical factors to hold the machining speed, precision, and productivity, therefore, it is critical that the suitable concept of the structure is chosen in the conceptual and fundamental design stage process because $80 \%$ of the final cost and quality of a product are designed in this phase $[11,12]$. Therefore, to design a suitable machine tool structure with high static, dynamic, and thermal features is very essential. In order to evaluate the configuration of machine tools, Kono et al.[13] developed the IWF Axis Construction Kit (ACK), which can realize the rigid body simulations and simple elastic body simulations of the machine tool. Ersal et al.[14] proposed a modular modeling approach for the design of reconfigurable machine tools (RMT), this models can be used for the evaluation, design and control of the RMT servo axes. Park and Sohn [15]developed 
an integrated design system for structural design of machine tools, the system is a knowledge-based design system and has three machine-tool-specific functional modules, including: configuration design and analysis, structural element design, and structural analysis support module. The system make the machine structure design quickly and conveniently. Woong et al. [16] developed an intelligent software system which can support efficiently and systematically machine tool design by utilizing design knowledge. Chen et al.[17] used the integrated design method developed an ultra precision flycutting machine tool, three configurations (horizontal, gantry, pyramid) are selected from the configuration library in the design stage as the candidate configurations, according to the functional requirements of the machine tool. The best configuration is selected considering the dynamic performance. While in the previous study, the research of the precision machine tool are mainly focused on the machine detail design and performance analysis [18-20], the systematic conceptual and fundamental design method are rarely reported. In this paper, an integrated system for ultra precision machine tool design in conceptual and fundamental design stage is developed for shorten the design time and improving the reliability of the precision machine tool.

\section{Integrated system for ultra-precision machine tool design}

\subsection{Conceptual and fundamental design process of a machine tool}

Precision machine tools are a high standard of precision system in order to sustain the required accuracy, productivity and repeatability. The precision of a machine is affected by the positioning accuracy of the cutting tool with respect to the 
workpiece surfaces and their relative structural and dynamics loop precisions, which are fundamental and essential for the machine design. Therefore, the stiffness loop of the machine tool and motion error of the machine tool must be considered in the machine tool configuration design stage. In addition, dynamic and thermal performances of machine tools such as vibration are one of the crucial problems in high precision machining. Since dynamic and thermal properties of machines are greatly influenced by the machine configuration, the configuration should be evaluated very early in the design phase [21]. However, only few manufacturers use evaluation tools in order to check configuration variants [22]. In summary, the main factors must be considered for precision machine tool design in conceptual and fundamental design stage are listed as follows:

$>$ The stiffness budget of the machine tool

$>$ The dynamic performance

$>$ The thermal performance

$>$ The error budget of the machine tool.

The conceptual and fundamental design process of a machine tool structure is divided into four steps, i.e., proposal, modeling, analysis, and selection as shown in Fig.1. In step 1, several machine tool configurations are proposed according to the design requirements. Mathematical models for each structure are established in step 2 to prepare for the analysis in step 3. Step 3 analyzes the stiffness chain, dynamic and thermal performance and the error budget of these configurations proposed in step 1. In step 4, the superior configuration is selected based on analysis results. Therefore, 
the structural design efficiency in the conceptual and fundamental stage is improved significantly.

\subsection{Integrated design system}

The integrated system for machine tool configuration design is introduced to facilitate the design process based on the experience and the simulation algorithm. The application flowchart of this system is illustrated in Fig. 2. To begin with, the functional requirements of the machine tool, such as the machining type, workzone, machining accuracy, the material of the workpiece, are input to the system. Next, the integrated system provide some configurations from the configuration library to select by the designer, and the designer also can add some novel configurations to the configuration library as candidate configurations, if they have some new ideas. The dimension of the machine tool in the configuration library with the ability to zoom in and out, in order to adapt to different working space. Following is the analysis process, firstly, a finite element model (FEM) for each candidate configuration of machine tool is built up automatic. The solid 186 element is used for the components of the machine tool, and the spring element spring-damp 14 is used to substitute for the bearings in the spindle and the slide, the matrix 27 elements are introduced to represent the linear motor of the slide in the driving direction. The corresponding boundary conditions are applied automatically, according to different analysis types; Secondly, the stiffness budget, the dynamic analysis, the thermal analysis and the error budget are carried out for each candidate configuration. Then, the analysis results of each candidate configuration are compared by a simplified rating system. 
This system has been designed to select more suitable configuration of the desired machine tool. For an operation factor $x_{i}$, there is a corresponding series of rating numbers: $\omega_{i 1}, \omega_{i 2}, \cdots \quad \ldots$. Each rating number corresponds to one of the candidate configurations. The rating shows which configuration satisfies the operation requirements best. Clearly, the set of operation factors $\left[x_{i}\right](i=1$ to 4$)$ can be expanded or reduced depending on each specific application. For a specific application, each operation factor $x_{i}$ corresponds to a different rating $\omega_{i}$ which provides the weighting for the importance of the factor in a particular application. For example, the stiffness has a large weighting in designing machine tool for the rapid machining, because the stiffness has a direct impact on the machining efficiency. Each candidate configuration is given a rating $\omega_{i}$ and $k_{i}$ for the particular application. A rating $R_{j}$ is given by equation (1):

$$
R_{j}=\sum_{i=1}^{9} w_{i j} k_{i} \quad(j=1,2, \cdots
$$

$w_{i j} k_{i}$ is the integrated rating for operation factor $x_{i}$ in a particular value of $j$.

The rating results $R_{j}$, for each candidate configuration are compared. The highest result $R_{j} \in \max \left\{R_{1}, R_{2}, \ldots \quad \ldots\right.$ yields the configuration which is recommended. Fig.3 illustrates the selection process as a selection network. At last, the most appropriate configuration is output to the designer.

3 Design case study: A hybrid ultra precision machine tool for hard material machining

In present, the integrated system is used for a hybrid ultra precision machine tool design. The function of the machine tool is designed for optical mould machining, it is 
expected to a hybrid machine tool which can achieve grading, laser machining and in-situ metrology.

The specifications of the machining components are listed in Table 1, the materials of the workpiece are silicon carbide and hard steel; the maximum size of the workpiece is $\Phi 150 \mathrm{~mm} \times 150 \mathrm{~mm}$; the optical surface forms are sphere, aspheric and free-from; the surface figure is no more than $1 \mu \mathrm{m} \mathrm{P}-\mathrm{V}$ on $150 \mathrm{~mm}$ surface, the roughness is less than $2 \mathrm{~nm}$.

According to the specifications of the machining components, the specifications of the hybrid ultra precision machine tool is designed as shown in Table 2.

\section{1 Candidate configurations proposing}

Three configurations are selected from the configuration library, according to the functional requirements of the machine tool, as shown in Fig.4 a-c). A novel configuration is also proposed by the designer, as shown in Fig.4 d).

\section{2 Performance analysis and configuration selection}

The stiffness budget of each configuration is shown in Fig.5, according to the stiffness of each component of the machine tool. It can be found that, the stiffness of the spindle are extremely weaker than the other components, therefore, the stiffness of the whole machine are mainly determined by the spindle stiffness. The configuration of the machine tool only has a negligible effect on the stiffness of such machine tool.

Error budget provides an estimate of potential errors within a machine axis that lead to deviations from the desired motion. The error budget is used as a method of evaluating the ability of a proposed machine axis configuration to meet the desired 
specification. An error budget analysis tool is built and integrated in the integrated system used at design stage to predict the geometric error of a machine system. The error budget of each configuration are output according to the specification and the physical dimension of the components used in each configuration. Fig. 6 shows the error budget of the configuration 1 as an example. It can be found that the Root Sum Square (RSS) of each direction are less than $4 \mu \mathrm{m}$, which indicate that the geometric error of the machine tool is good for ultra-precision machining. And from the output results, it can be noted that there are little difference among the four configurations, because of the similar specification and the physical dimension of the components.

The modal analysis are carried out by the integrated system as shown in Fig.7, the results show that the column type has the worst dynamic performance $113 \mathrm{~Hz}$, while the gantry type has the best dynamic performance $201 \mathrm{~Hz}$, therefore, for the ultra-precision machining in order to improve the dynamic performance the closed configuration is preferred.

In order to evaluate the thermal performance of the candidate configurations, in the thermal analysis module, the thermal sensitivity of the configurations are carried out, the evaluation indicator is the deformation between the tool-tip and the workpiece under the ambient air temperature change from $20^{\circ} \mathrm{C}$ to $21^{\circ} \mathrm{C}$ in an hour. From Fig.7, it can be found that the horizontal type is very sensitive to temperature, the deformation up to $1.3 \mu \mathrm{m}$, the column type is $1.2 \mu \mathrm{m}$, the pyramid type is $0.8 \mu \mathrm{m}$, and the gantry type is $0.6 \mu \mathrm{m}$.

The calculate results of the four analysis module are transferred to the evaluation 
system, and the evaluation results are output by the rating system, the gantry configuration is the best one, follows by the pyramid and horizontal configurations, and the column type is the worst one for ultra-precision machining, therefore, the gantry configuration is recommended as the final configuration for the hybrid ultra-precision machine tool.

\section{Conclusion:}

The paper presents an integrated system for ultra precision machine tool design in the conceptual and fundamental design stage. The proposed expert design strategy is demonstrated by two ultra precision machine tools design. The following conclusions are drawn:

1. The integrated system for conceptual and fundamental design of a machine tool configuration is established is based on the dynamics, thermodynamics and error budget theory. The configuration design efficiency in the conceptual and fundamental stage is improved significantly.

2. The integrated design system achieves machine tool configuration design by comparison and comprehensive evaluation the performances of each candidate configurations for the perspective of dynamics, thermodynamics and error, an appropriate configuration is given, which provides a benchmark and guiding significance for the design of the ultra precision machine tool.

3. The integrated design system is successful used for a hybrid ultra precision machine tool for hard material machining, the results validate the developed system is effective and efficient in optimizing the design of ultra precision machine tool in the 
conceptual and fundamental design stage.

\section{Acknowledgment}

The authors gratefully acknowledge financial support of the EPSRC (EP/K018345/1), The Sino-UK Higher Education Research Partnership for PhD Studies program, and China Scholarship Council (CSC).

\section{Reference}

[1] Luo X, Cheng K, Webb D, et al. Design of ultra-precision machine tools with applications to manufacture of miniature and micro components. Journal of Materials Processing Technology 2005; 167(2-3): 515-528.

[2] Shore P, and Morantz P, Ultra-precision: enabling our future. Phil. Trans. R. Soc. A 2012; 370: 3993-4014.

[3] Brinksmeier E, Mutlugünes Y, Klocke F, et al. Ultra-precision grinding. Annals of CIRP 2010; 59(2):652-671.

[4] Schellekens P and Rosielle N, Design for precision: current status and trends. Annals of CIRP 1998; 47(2): 557-584.

[5] Wybranski B, Micro production technologies. mstNews 2004; 2:43-45.

[6] Huo D and Cheng K, A dynamics-driven approach to the design of precision machine tools for micro-manufacturing and its implementation perspectives. Proc IMechE Part B J Eng Manuf 2008; 222(1):1-13.

[7] Schellekens P and Rosielle N. Design for precision: current status and trends. Annals of the CIRP 1998; 47(2): 557-584.

[8] Slocum AH, in: Precision Machine Design, Englewood Cliffs, Prentice Hall, 1992. 
[9] Bianchi G, Paolucci F, Braembusshe PV, et al. Towards Virtual Engineering in Machine Tool Design. Annals of the CIRP, 1996; 45(1): 381-384.

[10] Liang Y, Chen W, Sun Y, et al. Dynamic design approach of an ultra-precision machine tool used for optical parts machining. Proc IMechE Part B: J Engineering Manufacture 2012; 226(11) 1930-1936.

[11] Homann BS and Thornton AC, Precision Machine Design Assistant: A constraint-based Tool for the Design and Evaluation of Precision Machine Tool Concepts. Artificial Intelligence for Engineering Design, Analysis and Manufacturing, 1998; 12(5): 419-429.

[12] Yu Z, Nakamoto K, Ishida T, et al. Interactive Design-Assistance System of Machine Tool Structure in Conceptual and Fundamental Design Stage. Int. J. of Automation Technology 2010; (4)3: 303-311.

[13] Konoa D, Lorenzerb T, Weikertc S, et al. Evaluation of modelling approaches for machine tool design. Precision Engineering 2010;34(3): 399-407.

[14] Ersal T, Stein J and Louca L. A Modular Modeling Approach for the Design of Reconfigurable Machine Tools. American Society of Mechanical Engineers, Manufacturing Engineering Division, MED. 2004;15:393-399.

[15] Park M, Sohn Y. Development of Integrated Design System for Structural Design of Machine Tools, Advances in Design Springer Series in Advanced Manufacturing 2006, 547-558

[16] Woong M, Cha J, Park J, et al. Development of an Intelligent Design System for Embodiment Design of Machine Tools, Annals of the CIRP, 1999; 48(1):329-332. 
[17] Chen W, Liang Y, Sun Y, et al. Design philosophy of an ultra-precision fly cutting machine tool for KDP crystal machining and its implementation on the structure design. Int J Adv Manuf Technol 2014;70(1-4): 429-438.

[18] Wang ZG, Cheng X, Nakamoto K, et al. Design and development of a precision machine tool using counter motion mechanisms. Int J Mach Tools Manuf 2010; $50(4): 357-365$

[19] Takahashi M, Yoshioka H and Shinnoo H. A newly developed long-stroke vertical nano-motion platform with gravity compensator. J Adv Mech Design Systems Manuf 2008; 2(3):356-365

[20] Brecher C, Utsch P, Klar R, et al. Compact design for high precisionmachine tools. Int J Mach Tools Manuf 2010; 50(4):328-334

[21] Kono D, Lorenzer T, Weikert S, et al. Evaluation of modelling approaches for machine tool design. Precision Engineering 2010; 34(3): 399-407.

[21] Cheng K, in: Machining dynamics-Fundamentals, Applications and Practices. Appl Pract 2009. 


\section{Figure captions:}

Fig. 1 Conceptual and fundamental design process of a machine tool

Fig.2 Integrated design system

Fig.3 The configuration selection network

Fig.4 The candidate configurations of the machine tool

Fig.5 Stiffness budget of each configuration

Fig.6 The error budget for column configuration

Fig.7 Dynamic and thermal performances analysis 
Table captions:

Table 1. Specifications of the machining components

Table 2. Specifications of the hybrid ultra precision machine tool 
Fig.1

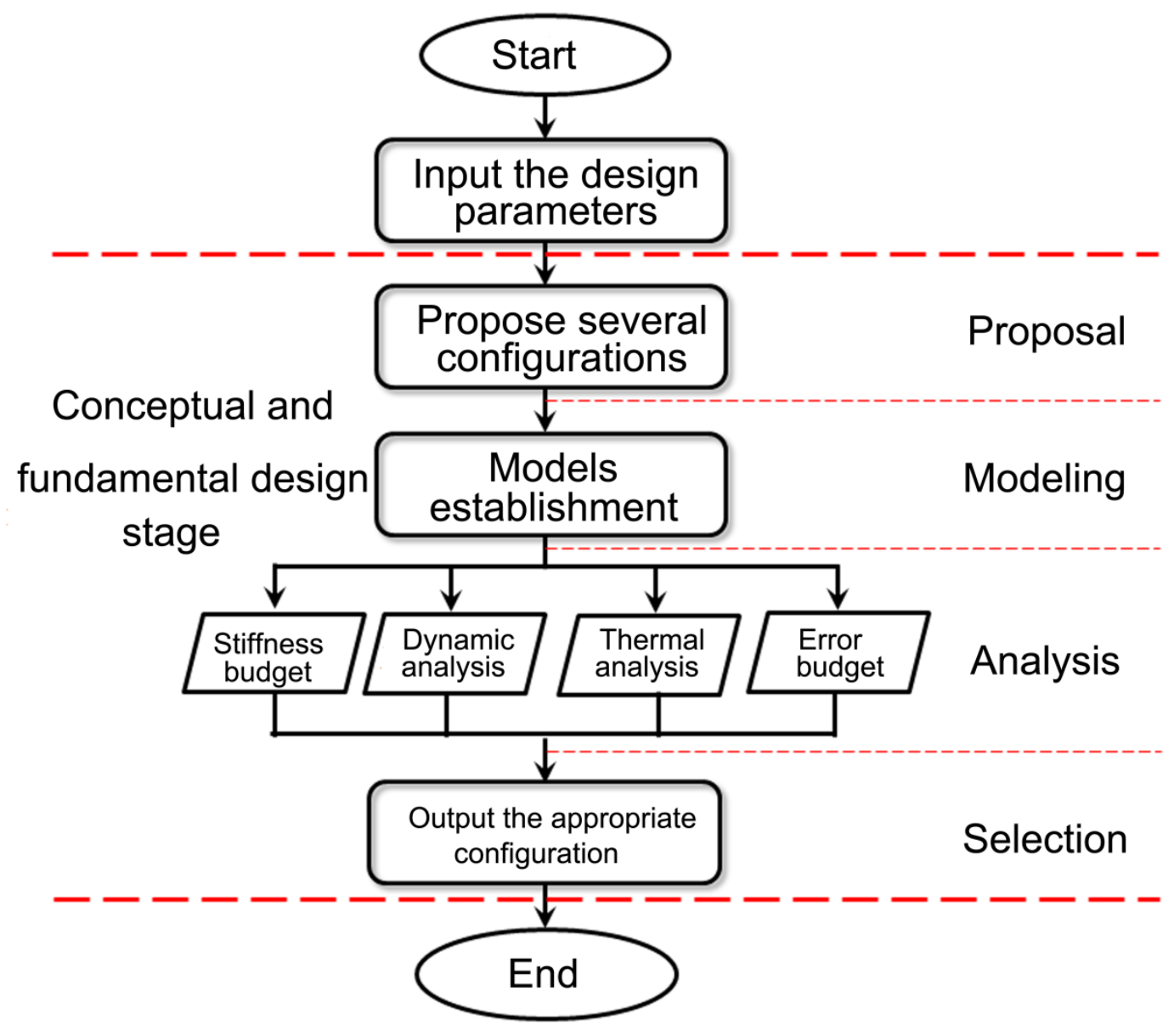


Fig. 2

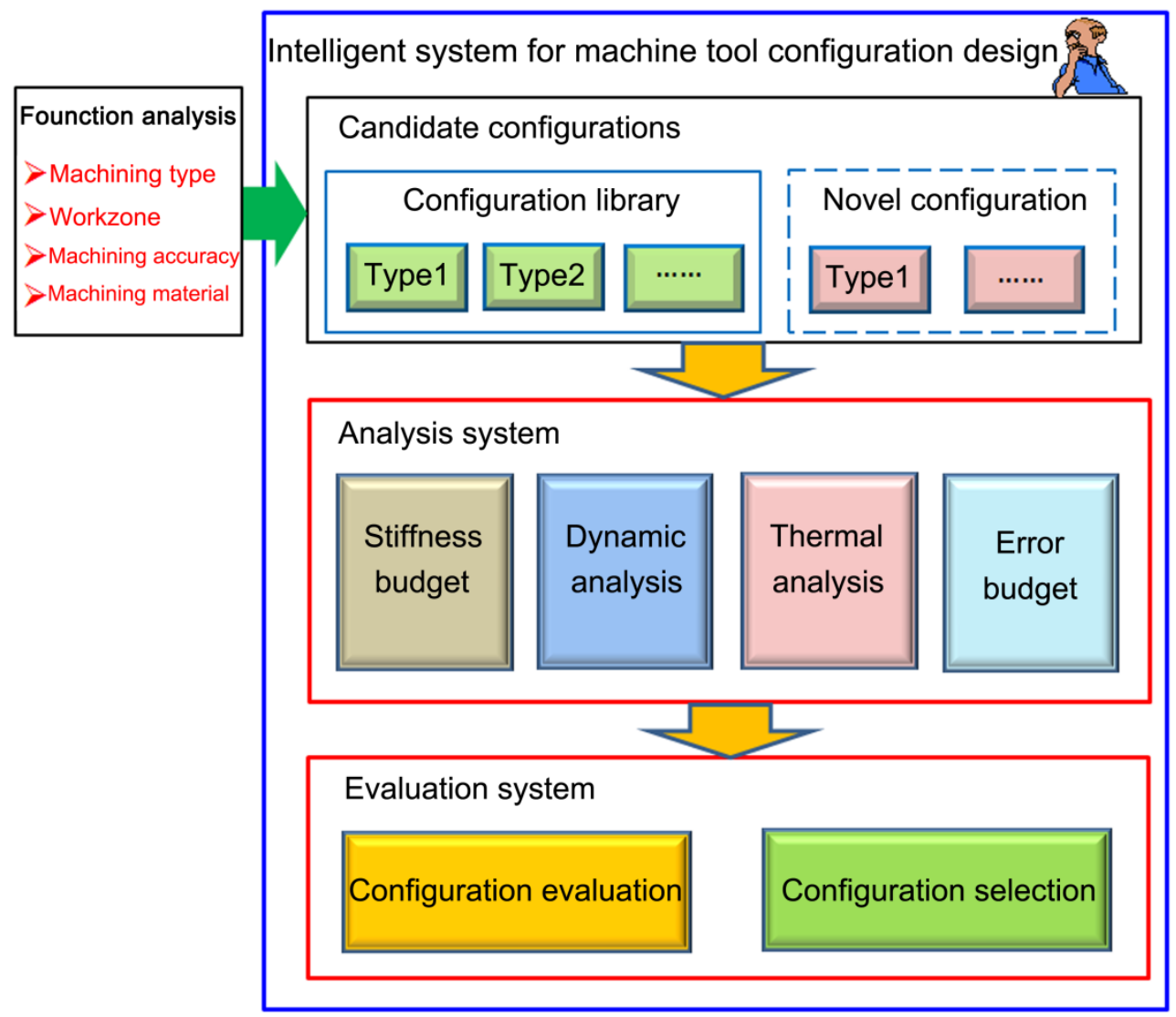


Fig. 3

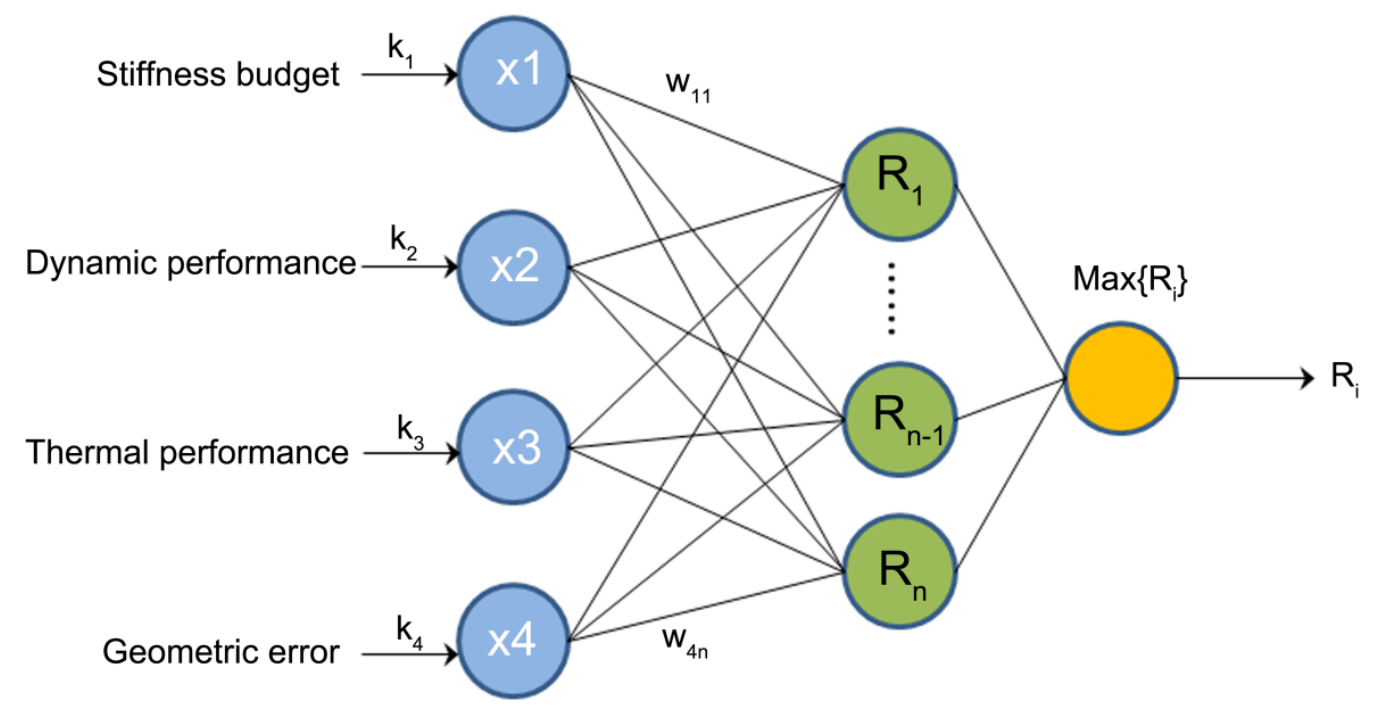


Fig.4

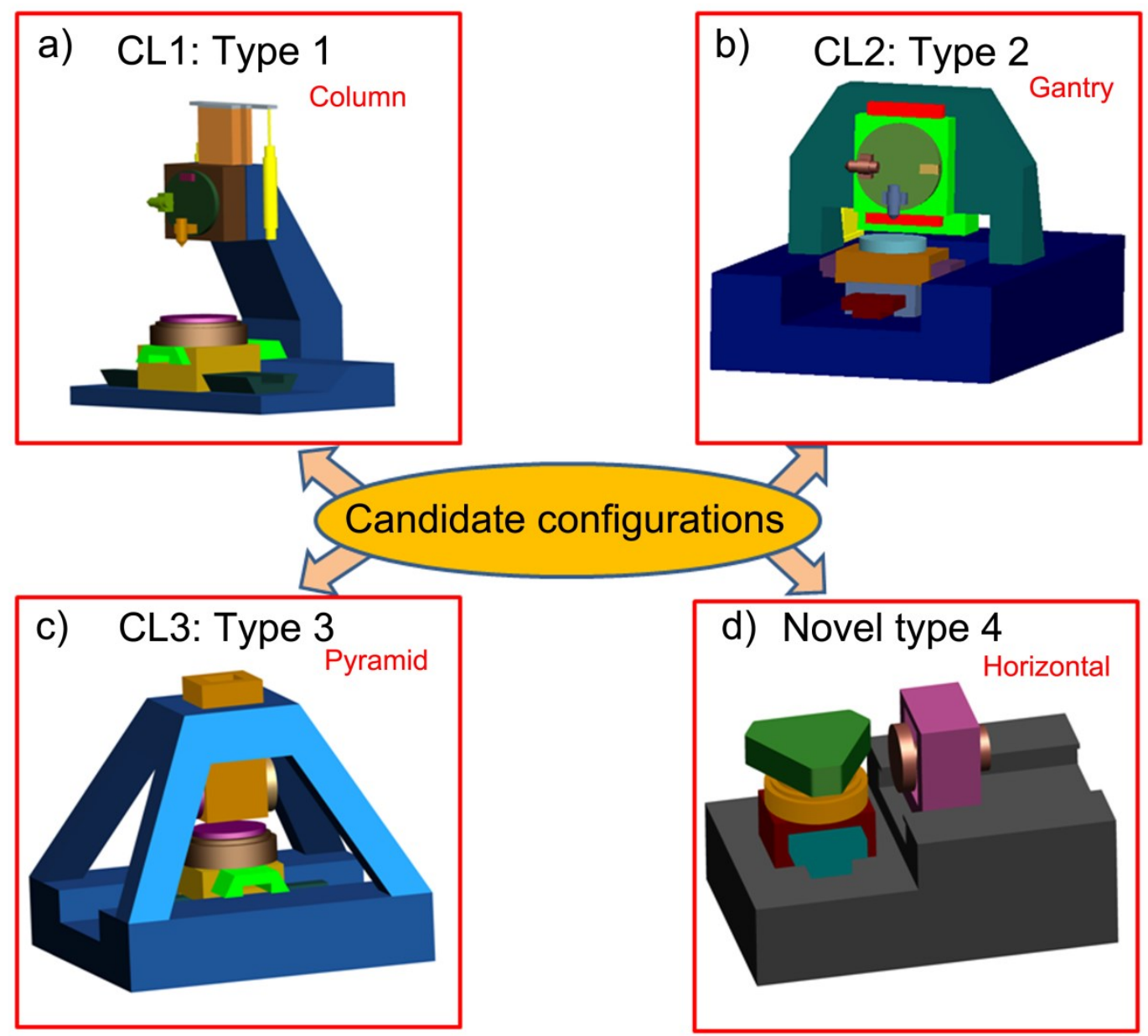


Fig.5

\begin{tabular}{|l|r|r|r|}
\cline { 2 - 5 } \multicolumn{4}{c|}{ Stiffness (N/um) } \\
\hline & x stiff. & y stiff. & z stiff. \\
\hline X Axis & - & 240 & 320 \\
Y Axis & 240 & -- & 320 \\
C Axis & 60 & 60 & 190 \\
Z Axis & 300 & 420 & - \\
B Axis & 80 & 250 & 80 \\
Spindle & 4 & 4 & 5 \\
\hline Total & 3.4883721 & 3.6073177 & 4.4640235 \\
\hline
\end{tabular}

\begin{tabular}{|l|r|r|r|}
\cline { 2 - 4 } \multicolumn{4}{|l}{ Stiffness (N/um) } \\
\hline & x stiff. & y stiff. & z stiff. \\
\hline X Axis & -- & 240 & 320 \\
Y Axis & 240 & -- & 320 \\
C Axis & 60 & 60 & 190 \\
Z Axis & 300 & 420 & -- \\
B Axis & 80 & 250 & 80 \\
Spindle & 4 & 4 & 5 \\
\hline Total & 3.4883721 & 3.6073177 & 4.4640235 \\
\hline
\end{tabular}

\begin{tabular}{|c|c|c|c|}
\hline \multirow[t]{2}{*}{ c) } & \multicolumn{3}{|c|}{ Stiffness (N/um) } \\
\hline & $\mathrm{x}$ stiff. & y stiff. & $z$ stiff. \\
\hline $\mathrm{X}$ Axis & -- & 320 & 240 \\
\hline Y Axis & 240 & -- & 320 \\
\hline C Axis & 60 & 60 & 190 \\
\hline Z Axis & 200 & 320 & - \\
\hline B Axis & 80 & 250 & 80 \\
\hline Spindle & 4 & 4 & 5 \\
\hline Total & 3.4682081 & 3.6111947 & 4.4433618 \\
\hline
\end{tabular}

\begin{tabular}{|l|r|r|r|}
\cline { 2 - 5 } \multicolumn{4}{|c|}{ Stiffness (N/um) } \\
\hline & x stiff. & y stiff. & z stiff. \\
\hline X Axis & -- & 320 & 240 \\
Y Axis & 240 & -- & 320 \\
C Axis & 60 & 60 & 190 \\
Z Axis & 300 & 420 & -- \\
B Axis & 80 & 250 & 80 \\
Spindle & 4 & 4 & 5 \\
\hline Total & 3.4883721 & 3.6209238 & 4.4433618 \\
\hline
\end{tabular}


Fig.6

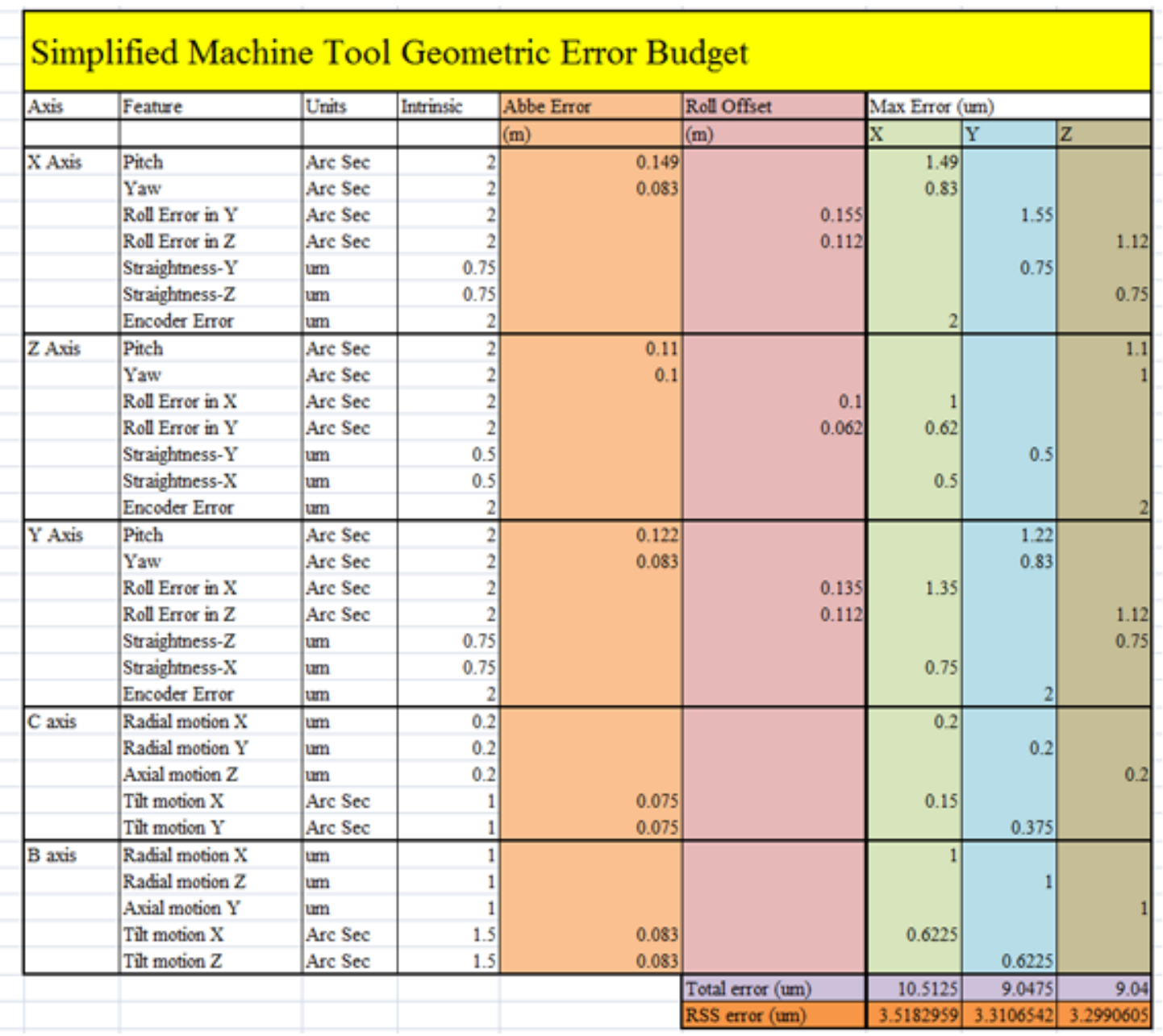


Fig. 7

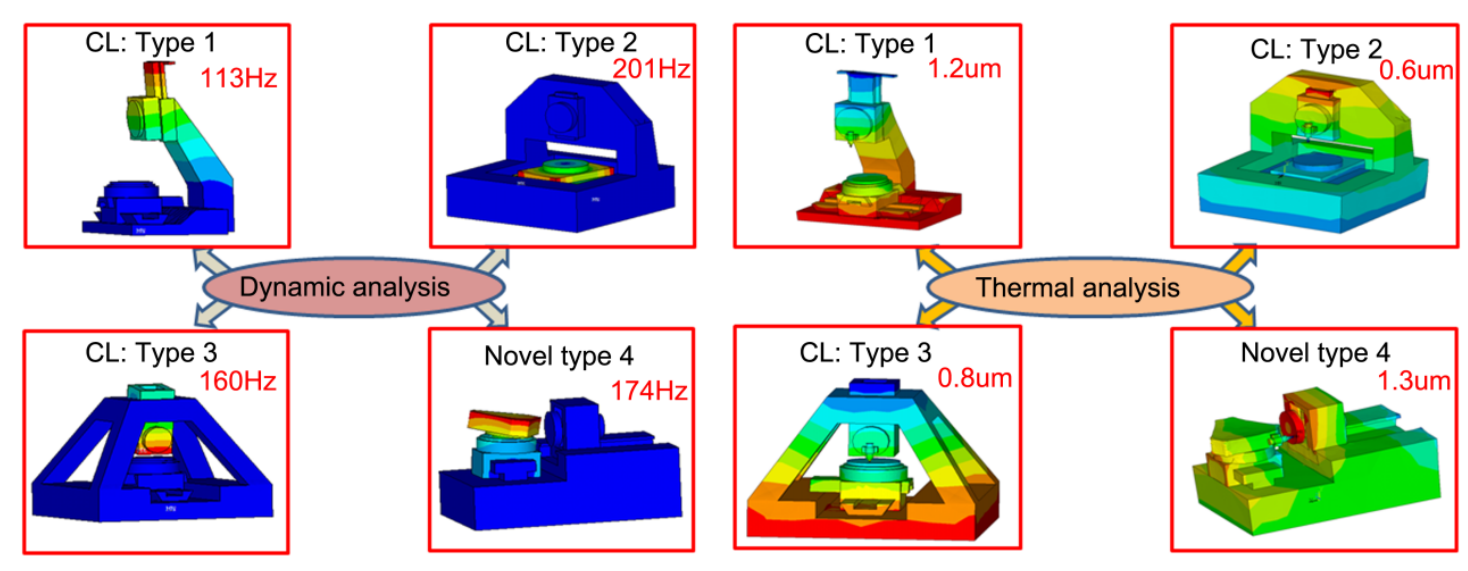


Table 1

Table 1 Specifications of the machining components

\begin{tabular}{|c|c|c|}
\hline \multicolumn{2}{|c|}{ Material } & SiC/Hard steel \\
\hline \multicolumn{2}{|c|}{ Size } & $\Phi 150 \mathrm{~mm} * 150 \mathrm{~mm}$ \\
\hline \multicolumn{2}{|c|}{ Optical Surface Forms } & Sphere, aspheric, free-form \\
\hline \multirow{2}{*}{ Surface qualities } & figure & $<1 \mu \mathrm{m}$ P-V on $150 \mathrm{~mm}$ surface \\
\cline { 2 - 3 } & roughness & RMS $<2 \mathrm{~nm}$ \\
\hline
\end{tabular}

Table 2

Table 2 Specifications of the hybrid ultra precision machine tool

\begin{tabular}{|c|c|c|c|c|c|c|}
\hline $\begin{array}{c}\text { Axes } \\
\text { number }\end{array}$ & Type & Stroke & Drive system & Motion accuracy & $\begin{array}{c}\text { Maximum } \\
\text { speed }\end{array}$ & Resolution \\
\hline X-axes & Air-bearing & $\begin{array}{r}230 \\
\mathrm{~mm}\end{array}$ & $\begin{array}{c}\text { Brushless } \\
\text { linear motor }\end{array}$ & $<1 \mu \mathrm{m}$ & $\begin{array}{c}3000 \\
\mathrm{~mm} / \mathrm{min}\end{array}$ & $5 \mathrm{~nm}$ \\
\hline Y-axes & Air-bearing & $\begin{array}{r}225 \\
\mathrm{~mm}\end{array}$ & $\begin{array}{c}\text { Brushless } \\
\text { linear motor }\end{array}$ & $<1 \mu \mathrm{m}$ & $\begin{array}{c}3000 \\
\mathrm{~mm} / \mathrm{min}\end{array}$ & $5 \mathrm{~nm}$ \\
\hline Z-axes & Air-bearing & $\begin{array}{r}150 \\
\mathrm{~mm}\end{array}$ & $\begin{array}{c}\text { Brushless } \\
\text { linear motor }\end{array}$ & $<1 \mu \mathrm{m}$ & $\begin{array}{c}1000 \\
\mathrm{~mm} / \mathrm{min}\end{array}$ & $2 \mathrm{~nm}$ \\
\hline B-axes & Air-bearing & $360^{\circ}$ & $\begin{array}{c}\text { DC brushless } \\
\text { torque motor }\end{array}$ & $<1$ arcsec & $300 \mathrm{rpm}$ & $\begin{array}{c}0.02 \\
\mathrm{arcsec}\end{array}$ \\
\hline C-axes & Air-bearing & \pm & $\begin{array}{c}\text { DC brushless } \\
\text { torque motor }\end{array}$ & $<10$ arcsec & $30 \mathrm{rpm}$ & $\begin{array}{c}0.02 \\
\mathrm{arcsec}\end{array}$ \\
\hline Spindle & Air-bearing & N/A & $\begin{array}{c}\text { DC brushless } \\
\text { motor }\end{array}$ & $\begin{array}{c}<1.0 \mu \mathrm{m} \text { axial } \\
\text { TIR and }<2.0 \mu \mathrm{m} \\
\text { radial TIR }\end{array}$ & $\begin{array}{c}200,000 \\
\mathrm{rpm}\end{array}$ & $\mathrm{N} / \mathrm{A}$ \\
\hline
\end{tabular}

